\title{
Technological and organizational operationalization of the program testing the operation of pyrotechnic entertainment articles of category 4, such as: aerial bombs and roman candles
}

\author{
Cristian Raul Cioara ${ }^{1 *}$, Marius Simion Morar ${ }^{1}$, Andrada Denisa Băbuț ${ }^{1}$, and Olga Miclea ${ }^{1}$ \\ ${ }^{1}$ National Institute for Research and Development in Mine Safety and Protection to Explosion - \\ INSEMEX Petroşani, 32-34 G-ral Vasile Milea St., 332047 - Petroşani, Hunedoara County, Romania
}

\begin{abstract}
The purpose of this paper is to describe how fireworks and their components are organized or built. Constructive details will facilitate the implicit or explicit descriptions of the operation and interconnection of several pyrotechnic objects for the purpose of organizing and conducting a firework show. The authors' approach to describing the organization and functioning of the fireworks runs into a difficulty: the large number and variety of pyrotechnic articles, making it difficult to deal with each product in detail, especially when new products may appear, with different physicochemical and effect characteristics. However, based on our own experience, we have applied a system to generalize certain explanations by category of pyrotechnic objects and by type of effects.
\end{abstract}

\section{Introduction}

Fireworks or pyrotechnic articles are pyrotechnic mechanical assemblies intended to generate a wide range of pyrotechnic effects: noise, white or coloured light, white sparks or coloured effects, smoke of different colours, specific time delays, etc. Each pyrotechnic effect is obtained as a result of the successive, controlled combustion of layers of pyrotechnic compositions loaded in various forms into mechanical elements (cylindrical or spherical bodies made of different materials).

This paper presents a technical and scientific approach to the concept of operationalization of the F4 category pyrotechnic testing activity, from the point of view of ensuring the security of the effects generated by the execution of fireworks with these types of pyrotechnic products.

The Technical Rule of Law 126/1995 states from a legal point of view the classification of pyrotechnic articles by categories according to the level of the risk and the noise level considering the place of use and their destination.

\footnotetext{
* Corresponding author: cristian.cioara@insemex.ro
} 
European Directive 2004/29 / EU on pyrotechnic articles transposed at national level by GD 1102/2014 includes: rules aimed at achieving the free movement of pyrotechnic articles and at the same time ensuring a high level of protection of human health and safety public health and consumer protection and safety, taking into account applicable environmental protection issues; the essential security requirements that pyrotechnic articles have to meet in order to be placed on the market.

Under this Directive, pyrotechnic articles are classified by manufacturers according to their type of use or their purpose and level of risk, including their noise level.

Testing of pyrotechnic articles for professional use (category F4) implied the use of stateof-the-art test infrastructure within the INCD-INSEMEX Petroşani Polygon, consisting of: concrete firing platform, firing system, video surveillance system and results processing, ensuring accurate precision for the ascension, the magnitude of the bursting effect and possible angular deviations from the optimal trajectory.

\section{Description of pyrotechnic articles for professional use of roman candles and air bombs}

\subsection{The general characteristics of the roman candle light pyrotechnic articles}

Roman candles are in the form of a cylindrical cardboard tube with diameters of 10 to $75 \mathrm{~mm}$ and various lengths. Inside the cylindrical body there are successively arranged multiple drilling loads and pyrotechnic compositions (typically $8 \div 10$ ), with various effects, separated by filling layers made of felt, sawdust or other slightly inert materials. Through these layers, pyrotechnic delayers are introduced on the centre axis, which performs both the delay and the transmission of the flame between two successive loads. (Fig.1)

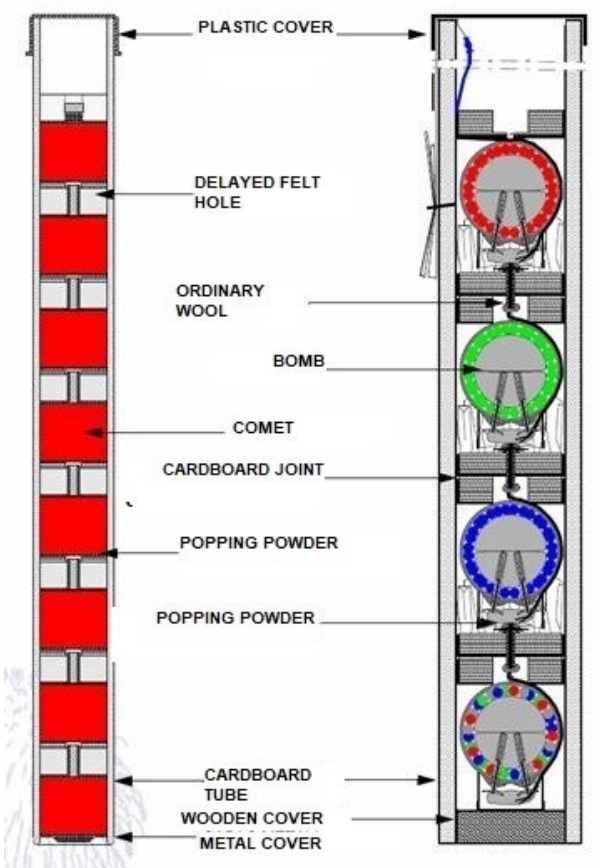

Fig. 1. The basic structure of roman candles. 
Among the most commonly used effects, we can mention three categories:

- The throwing of colourful stars: sparkles, comets or comets with fragmentation.

- Bombing: bombs with coloured shots or sound effects generators.

- The throwing of pyrotechnic elements with sound and / or visual effects, consisting of loads of compressed pyrotechnic compositions, for volcanoes, snakes or whistles effect.

\subsection{General characteristics of flying bombs pyrotechnic articles}

Regardless of their size, flying bombs are built on the same principle: they are propelled or thrown with the help of a mortar. Initial speed delivery is achieved by combustion of the black-powder spinning load which is placed in a glass of paper attached to the bottom of the bomb. (Fig. 2a, b)

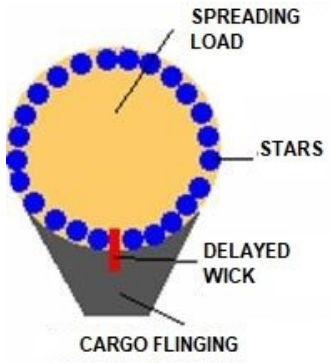

a.

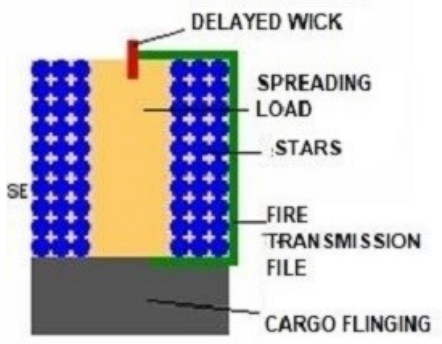

b.

Fig. 2. The aerial bomb constructive scheme (a-spherical bomb and b-cylindrical bomb).

Under the action of the gases pressure generated by the combustion of the overflow load, the bomb moves into the mortar pipe. Hot gases cause the ignition relay, part of the flying bomb, to ignite. Due to the printed speed, the bomb leaves the mortar and begins the ascent.

After a predetermined time, depending on the type and length of the pyrotechnic retarder, the flame is transmitted to the explosion or scattering charge, with the ignition of the stars in the pyrotechnic charge of the bomb. The pyrotechnic retarder is designed so that the burst of the bomb takes place in the maximum area of its trajectory.

Depending on the chemical compositions of the star effects in the composition of the bomb, its cover and the mass of the explosion charge, different acoustic and luminous effects can be generated.

There are at this time an extremely large number of types of bombs, depending on the pyrotechnic effects generated. However, it is possible to classify them by type of dispersed element, as follows:

- Colour effect bombs: the effects of coloured light are due to the combustion of stars (compressed pyrotechnic) in the air; the colours vary, depending on the chemical composition of the pyrotechnic mixtures;

- Bombs with thunderous acoustic effect: the acoustic effects are generated by compositions that are manifested by rapid deflagrations followed by the release of a short light signal (flash); these bombs are used to signal the change of the pace of the fireworks, the end of a fireworks set or the end of the pyrotechnic show (bombs with sound effect);

- Bombs with acoustic whistle effect: the acoustic effects are generated by pyrotechnic parts of the bombs, which allow through holes a high-speed gas leakage, with a specific whistling effect; if they leave and release sparks, the pieces are called snakes;

- Repeated bombs: the effect is generated by the insertion into a "mother" bomb of several smaller caliber bombs, which generate acoustic and luminous effects; 
- Tail bombs: the effect is generated by the arrangement on the body of the bomb of a tablet of pyrotechnic composition (tracer), whose combustion allows to obtain a spark jet, with a sufficient burning time to draw the upward trajectory of the bomb;

- Volcano bombs: effect obtained by the dispersion of tablets that leave traces of jets that trace the path of the tablets during their combustion.

\section{Evaluation of the requirements regarding the use of pyrotechnic articles for professional use, such as roman candles and flying bombs}

The advantage of using roman candles is that, using a single mortar, a large number of loads are launched, with only one start command required.

The disadvantages of roman candles are related to the higher cost price and the impossibility of changing the timing of the hits.

Roman candles are ideal especially for small and medium sized outdoor fireworks, where you want to launch a large number of loads without having to use a complex control system and / or perfect timing of the shots relative to an artistic program.

\subsection{Use of roman candles}

Roman candles can be installed in two distinct ways:

- Fixed by a vertical support, solid and stable, in three points of support, with the help of the adhesive strips of packaging, the plastic collars or the metallic wires; when using metal wire, to secure the candle, care must be taken that the tightening does not cause tube chokes that prevent the normal operation of the pyrotechnic object; (Fig. 3)

- Inserted into a mortar battery; for candles larger than $30 \mathrm{~mm}$, a solid support must be provided in contact with the bottom of the tube (the floor, the bottom of a mortar, etc.) to prevent desertification of the lower lid of the candle. (Fig. 4).

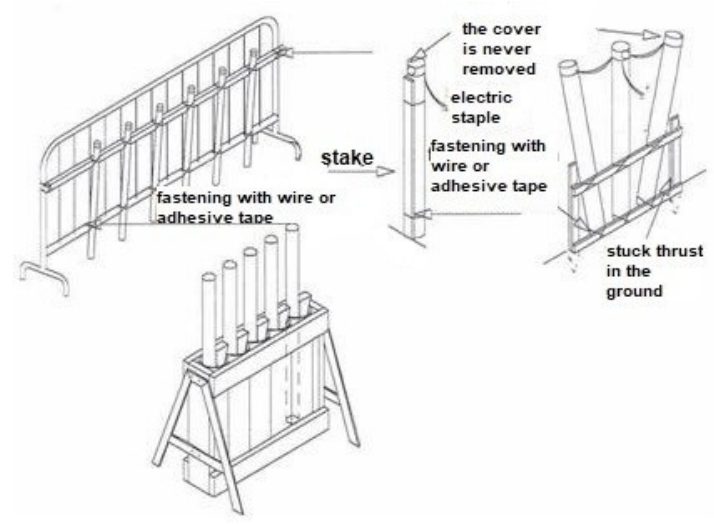

Fig. 3. Mounting variants of roman candle batteries. 


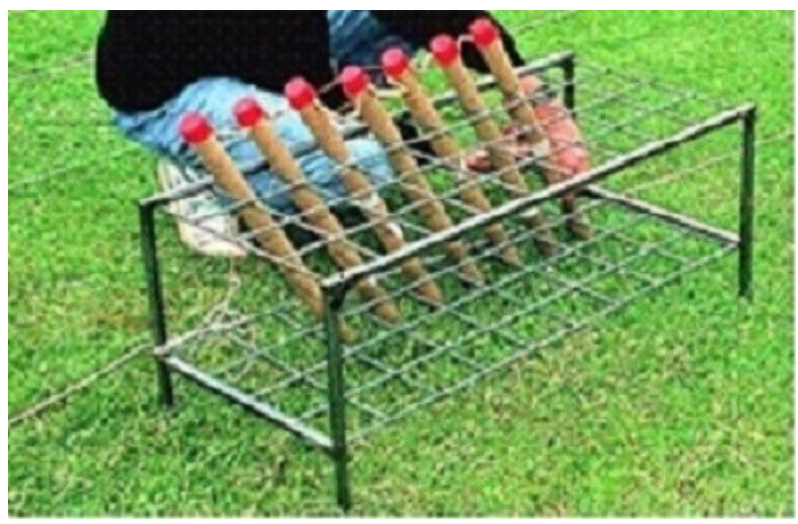

Fig. 4. Mounting an inclined battery by roman candles.

For roman candles of $75 \mathrm{~mm}$ or more, it is recommended that they be inserted in the sand. If they are mounted in the supports described above, they must be arranged in an area with height protection walls at least equal to their height.

The protective caps of the roman candles should not be undone, they are an integral part of the pyrotechnic object.

\subsection{Use of air bombs. The shot tubes.}

Flying bombs are drawn from the shot tubes. These are cylindrical tubes closed at one end.

The shot tubes have taken the name of military technical products that are used to fire on targets placed at relatively small distances (of the order of 2-10 km). Military-grade mortars shoot at high elevator angles and use inclined trajectories for mortar bombs, which are thrown at relatively low speeds from smooth pipes.

The shot tubes can be made of steel, plastic, fiberglass reinforced resin, multilayered cardboard, etc.

Special strength requirements for the shot tubes are imposed when using repetitive cylindrical pumps.

- Repeat bombs with a calibre of more than $75 \mathrm{~mm}$ cannot be used in cardboard shot tubes.

- For larger gauges, steel pipes are recommended, unless manufacturers specify another type of shot tubes.

Regarding their size, the size of the shot tubes is a few mm larger than the bomb, thus allowing the bomb to move freely during blasting. It is recommended to have a leeway space of about $5 \mathrm{~mm}$ between the bomb and the shot tubes. The length of the shot tubes has a positive influence on the initial throwing rate and, consequently, the altitude at which the flying bomb operates. It is recommended that the length of the shot tubes be 6-7 times its size.

The shot tubes with metal pipes for firing salute bombs are forbidden. This is due to the fact that in case of accidental initiation of the bomb in the shot tubes, high kinetic energy cutting sketches may appear, which may cause loss of human life.

Before placing and installing the shot tubes on the ground, it is necessary that the pyrotechnicist know the arrangement of the public and the directions from which the wind blows. This information will make it easier for the shot tubes placement mission because it has to provide a slight inclination of $5 \div 10^{\circ}$ of the pipes in relation to the vertical and in the opposite direction to the public.

If the wind speed can be greater than $6 \mathrm{~m} / \mathrm{s}$, then this inclination angle should be higher and even reach $20^{\circ}$. 
The location of the shot tubes or shot tubes batteries must be open, without the presence of trees, electrical grids or any other obstacle that may arise in the path of the bombs.

No shot tubes should be located near high-risk targets: gas stations, flammable materials depots, motor vehicles, etc.

After installing the shots tubes, it is mandatory to mark the dangerous area, in which the access of persons except pyrotechnics is prohibited. The marking is done with red or similar colour strip.

It is advisable to install on the mouth of the mortars some bands that indicate that the shot tubes has left the bomb. This remotely favours the indication of bomb operation.

Shot tubes batteries in the fan are generally used for firing in the salvo (at the same time) or at small time delays (right batteries).

In order to obtain the controlled delay times, the bombs can be assembled by introducing pyrotechnic retarders. The delay times must be chosen according to the desired firing mode.

It should also be noted that all the shot tubes (single or battery-linked shot tubes) must be permanently protected from rain and atmospheric humidity, usually by coating. It is recommended to use thin films of polyethylene.

To ensure the protection against incandescent debris falling to the ground after the operation of the other shot tubes, it is advisable to protect the shot tubes mouth by additional coating with an aluminium foil.

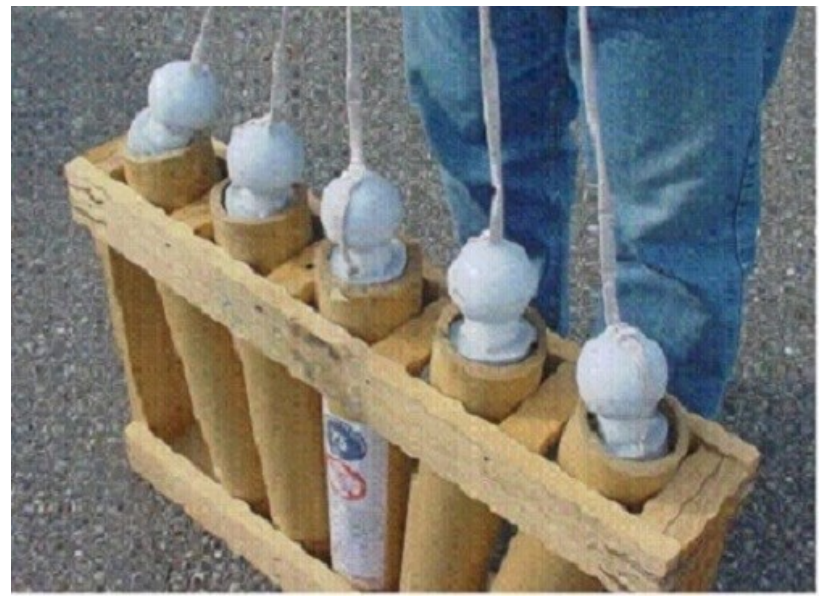

Fig. 5. Inserting bombs into a shot tubes mortar battery in fan.

\subsection{Safety distances for aerial bombs category F4}

When organizing the fireworks, the safety distances recorded in the instructions for use or on the packaging of the products will be permanently respected. In the case of an unmarked pyrotechnic object or with an illegible label it should not be used immediately, being necessary to identify the original packaging.

In normal climatic situations (absence of wind or wind less than $15 \mathrm{~m} / \mathrm{s}$ ), the following rules for calculating safety distances will apply:

- safety distance $=0,8 \times$ average operating height (rounded to the nearest multiple of 10);

- minimum safety distance $=8 \times 100 \times$ bomb size in $\mathrm{mm}$.

\subsubsection{Case Study:}

- for a $100 \mathrm{~mm}$ caliber bomb with an average burst height of $110 \mathrm{~m}$, the safety distance is 


$$
110 \times 0.8=88 \mathrm{~m} \text {, so } 90 \mathrm{~m} \text {. }
$$

- for a $100 \mathrm{~mm}$ caliber bomb with an average breaking height of $90 \mathrm{~m}$, the safety distance is

$$
90 \times 0.8=72 \mathrm{~m} \text {, so } 70 \mathrm{~m} \text {. }
$$

At the same time, this distance cannot be considered satisfactory if the second condition for the safe distance is not met:

$$
D=8 \times 100 \times 100=80,000 \mathrm{~mm}=80 \mathrm{~m} .
$$

It will always be considered as the safe distance, the highest result obtained by the two calculation methods.

\section{Conclusions}

This paper shows how the pyrotechnic articles for professional use in category F4 (roman candles and aerial bombs) and their component elements are organized or constructed. Thus, we present the concept of operationalizing the activity of using pyrotechnic articles in category F4, from the perspective of ensuring the security premises of the effects generated after the fireworks execution with these types of pyrotechnic products.

In accordance with the standardized requirements, for the testing of pyrotechnic articles for professional use (category F4), it was necessary to use the latest generation test infrastructure within the INCD-INSEMEX Petroșani Polygon provided with: concrete firing platform, firing system, surveillance system video and processing of the results that ensure an adequate accuracy for the ascension determination, the magnitude of the breaking effect and the possible angular deviations from the optimal trajectory.

In the safe organization and realization of fireworks, it is necessary to comply with the security requirement regarding the respect of the safety distances inscribed in the instructions for use or on the packaging of the products.

\section{References}

1. M Sućeska, EXPLO5 computer program for calculation of detonation parameters, Proc. of 32nd Int. Annual Conference of ICT, Karlsruhe, pp. 110/1-110/13, (2001).

2. Directive 2013/29/EU (2013).

3. E. Gheorghiosu, E. Ghicioi, A Kovacs, C. Jitea, S. Ilici, C. Cioara, Monitoring the behaviour of fireworks to vibrations and the establishment of the mechanical conditioning influence, Applied Mechanics and Materials, vol. 430, pp. 108-112, (2013).

4. A. Kovacs, G. Vasilescu, Pyrotechnic training course, (INCD INSEMEX Petrosani, Romania, 2017).

5. Law 126/1995. (2002).

6. Nucleu Project, Research on the modernization of the technical and information facilities for the organization of qualification courses in the pyrotechnician profession, Nucleu Program, Project PN 1643 02 20. (INCD INSEMEX Petrosani, Romania, 2016-2017).

7. Nucleu Project, Research on the influence of microclimate factors on parameters of the products, while testing the functioning of pyrotechnic article, Nucleu Program, Project PN 16430304. (INCD INSEMEX Petrosani, Romania, 2017).

8. Standard EN $15947-\mathbf{1} \div \mathbf{5}$. (2016)

9. Standard EN 16261 - $1 \div$ 4. (2016)

10. G. Vasilescu, A. Kovacs, E. Ghicioi, D. Rus, E. Gheorghiosu, C. Jitea, T. Csaszar, Determination of noise level specific to pyrotechnic articles for professional use, in order to evaluate the level of professional risk, Applied Mechanics and Materials, vol. 801, pp. 96-101, (2015). 